\title{
Catástrofes creadas y su invisibilización en los contextos urbanos: la migración forzada al interior de las ciudades en Colombia
}

Création et invisibilisation de catastrophes dans l'espace urbain : la migration forcée dans les villes en Colombie Created catastrophes and their invisibility in urban contexts: forced migration in the cities of Colombia

Jorge Andrés Cancimance López

\section{(2) OpenEdition}

Edición electrónica

URL: http://journals.openedition.org/bifea/5942

DOI: $10.4000 /$ bifea. 5942

ISSN: 2076-5827

Editor

Institut Français d'Études Andines

Edición impresa

Fecha de publicación: 1 diciembre 2014

Paginación: 507-527

ISSN: 0303-7495

Referencia electrónica

Jorge Andrés Cancimance López, «Catástrofes creadas y su invisibilización en los contextos urbanos: la migración forzada al interior de las ciudades en Colombia », Bulletin de l'Institut français d'études andines [En línea], 43 (3) | 2014, Publicado el 08 diciembre 2014, consultado el 05 noviembre 2020. URL : http://journals.openedition.org/bifea/5942 ; DOI : https://doi.org/10.4000/bifea.5942

\section{(c)}

Les contenus du Bulletin de l'Institut français d'études andines sont mis à disposition selon les termes de la licence Creative Commons Attribution - Pas d'Utilisation Commerciale - Pas de Modification 4.0 International. 


\title{
Catástrofes creadas y su invisibilización en los contextos urbanos: la migración forzada al interior de las ciudades en Colombia*
}

\author{
Jorge Andrés Cancimance López**
}

\begin{abstract}
Resumen
El cambio en las lógicas del conflicto armado en Colombia, en cuanto a escenarios, objetivos, actores y estrategias bélicas, ha hecho que la migración forzada se transforme, de tal forma que actualmente no es posible hablar únicamente de las migraciones forzadas con trayectorias campo-ciudad (de lo rural a lo urbano), sino que se debe reconocer la existencia de una variación en esta lógica de movilidad impuesta: la migración forzada al interior de una misma ciudad. En Colombia, aún no se reconoce que la migración forzada al interior de sus espacios urbanos sea un fenómeno social que amerita el diseño de políticas públicas para atender el desastre que la violencia está creando en un entorno «civilizado»: la ciudad. En lo que sigue de este artículo me interesaré por esta temática.
\end{abstract}

Palabras clave: ciudad, migración forzada, Colombia, política pública, catástrofe

\section{Création et invisibilisation de catastrophes dans l'espace urbain : la migration forcée dans les villes en Colombie}

\section{Résumé}

Le changement de logiques du conflit armé en Colombie, en ce qui concerne les objectifs, acteurs, stratégies de guerre et scénarios, a fait évoluer les migrations forcées de telle manière qu'il n'est plus

* Una primera versión de este texto se hizo en el marco del proyecto de investigación: «Reconstrucción de la memoria histórica del desplazamiento forzado en Colombia», adelantado por el entonces Grupo de Memoria Histórica de la Comisión Nacional de Reparación y Reconciliación (juniodiciembre de 2011) y en el que el autor participó como consultor independiente.

** Candidato PhD en Antropología por la Universidad Nacional de Colombia. Maestro en Ciencia Política de la Facultad Latinoamericana de Ciencias Sociales sede Ecuador y Trabajador Social de la Universidad Nacional de Colombia. E-mail: jacancimancel@unal.edu.co 
possible aujourd'hui de parler de migrations forcées en se référant seulement aux trajectoires en provenance des campagnes vers les villes. Il est nécessaire de reconnaître l'existence d'une logique de migration imposée : la migration forcée à l'intérieur d'une même ville. En Colombie, la migration forcée intra-urbaine n'est toujours pas reconnue comme un phénomène social qui nécessite l'élaboration de politiques publiques pour faire face au désastre que la violence génère dans un espace « civilisé » : la ville. Cet article présente des pistes de recherche sur cette thématique.

Mots clés : ville, Colombie, migration forcée, politique publique, catastrophe

\title{
Created catastrophes and their invisibility in urban contexts: forced migration in the cities of Colombia
}

\begin{abstract}
The change in the logic of Colombian armed conflict — scenes, objectives, actors and warlike strategies - has made forced migration evolve in such a way that it is not possible now to talk only about forced migration from rural environments to urban ones but also about the existence of variations in these imposed mobility such as the forced migration inside the same city. In Colombia, forced migration among urban spaces is not recognized yet as a social phenomenon that requires public policies to cope with the disaster of violence that it is creating within a "civilized" urban setting.
\end{abstract}

Key words: city, forced migration, Colombia, public policies, catastrophe

La migración forzada intraurbana en Colombia ha sido definida recientemente como una tipología de migración forzada fruto del conflcito armado interno presente en este país desde hace más de medio siglo1, y de las conflictividades propias de la ciudad que integran a su vez violencias sociales, políticas y económicas (Codhes, 2013; 2014; Centro Nacional de Memoria Histórica, 2014). Estas violencias producen escenarios de conflicto y vulnerabilidad para las poblaciones en los que la única opción es huir del lugar de residencia trasladándose forzosamente a barrios periféricos de las ciudades en que las condiciones materiales, de vida y de seguridad resultan iguales o peores a las abandonadas, según muestran los informes de derechos humanos de la Defensoría del Pueblo colombiana (2006; 2004). Por lo tanto, es un fenómeno que da cuenta de la continuidad en los hechos violentos asociados con este conflicto, pero ahora en un escenario urbano. Como tal, y según señala la Consultoría para los Derechos Humanos y el DesplazamientoCodhes en su última publicación sobre esta temática, «muestra la necesidad de revisar la imagen de las urbes como zonas de seguridad, en oposición al mundo rural donde transcurre la confrontación armada» (Codhes, 2014: 7). Durante los

1 Según la Corte Constitucional Colombiana, el conflicto armado interno es: «Un fenómeno complejo que no se agota en la ocurrencia de confrontaciones armadas, en las acciones violentas de un determinado actor armado, en el uso de precisos medios de combate, o en la ocurrencia del hecho en un espacio geográfico específico, sino que recoge la complejidad de ese fenómeno, en sus distintas manifestaciones y aún frente a situaciones en donde las actuaciones de los actores armados se confunden con las de la delincuencia común o con situaciones de violencia generalizada» (Corte Constitucional, 2012: Sentencia C-781 de 2012). 
últimos diez años, este tipo de migración se ha convertido en uno de los retos más apremiantes con miras al logro de soluciones sostenibles para las víctimas.

Mi objetivo con este artículo es mostrar los principales comportamientos de esta modalidad de migración durante el periodo 1980-2011. Para ello, reviso cronológicamente desde cuándo y cómo dos actores (prensa e instituciones estatales) empiezan a referenciar este fenómeno. Mi propósito es aportar elementos analíticos para posteriores ejercicios investigativos relacionados con las políticas del suelo, el hábitat popular y la inclusión social de las víctimas de esta modalidad de violencia en las políticas locales, regionales y nacionales sobre la atención y la reparación. Está claro, en efecto, que la migración forzada al interior de las ciudades en Colombia es aún una temática ausente de un reconocimiento cabal tanto en las agendas investigativas como en las políticas de prevención del desplazamiento forzado y de atención, protección y reparación de las víctimas. En lo que sigue de este artículo me interesaré por abordar tres aspectos: i) la migración forzada campo-ciudad-ciudad como catástrofe humanitaria; ii) el proceso de reconocimiento de la migración forzada en la ciudad y un panorama nacional del comportamiento de esta modalidad de violencia; iii) la cronología de la movilidad forzada en los escenarios urbanos. Finalizaré con unos breves comentarios conclusivos.

\section{LA MIGRACIÓN FORZADA CAMPO-CIUDAD-CIUDAD COMO CATÁSTROFE HUMANITARIA}

Algunos investigadores (Naranjo, 2004; Uribe, 2002; Jaramillo et al., 2004; Bello \& Jiménez, 2008) afirman que la migración forzada representa una de las peores catástrofes humanitarias y de violación de derechos que existen en Colombia, y por lo tanto, llaman la atención sobre la necesidad urgente de una respuesta institucional más adecuada y el estudio sistemático de las implicaciones que este flagelo tiene para la sociedad colombiana, su territorio y, especialmente, para sus víctimas:

[...] el conflicto armado y la crisis humanitaria hacen del desplazamiento forzado un verdadero desastre humanitario, confirmándose como un asunto de carácter público, no sólo porque sea un problema que afecta a una cantidad considerable de personas, sino porque el desplazado es un ciudadano en el que se sintetiza la violación de todos sus derechos humanos, políticos y sociales, individuales, familiares y colectivos, de género y generación (Naranjo, 2004: 25).

Martha Bello \& Sandro Jiménez (2008) afirman que el Estado ha reconocido el fenómeno, ha asumido la responsabilidad de la atención al mismo y ha hecho un esfuerzo enorme por responder de manera adecuada. Sin embargo, aseguran también que estos esfuerzos se han quedado en el intento de atender la emergencia que representa la migración forzada como hecho, a través de la ayuda humanitaria de emergencia, sin ofrecer realmente una solución de restablecimiento a largo 
plazo, que le permita a las víctimas recuperar su dignidad, su cotidianidad, su proyecto de vida y superar esa situación —en un principio transitoria— de éxodo forzado.

Todos estos autores (Naranjo, 2004; Uribe, 2002; Jaramillo et al., 2004; Bello \& Jiménez, 2008) también se han encargado de mostrar las consecuencias e impactos de la migración forzada para las víctimas en general y en las ciudades, reafirmando la existencia de la violación sistemática de derechos y producción de vulnerabilidades que hace que sus víctimas, sean cada vez más vulnerables.

La población desplazada es el grupo más vulnerable entre los vulnerables, no solo por las carencias materiales que afronta al huir de su lugar de origen sino por el efecto que tiene el desarraigo en su capacidad de agenciar su propio proyecto de vida (Naranjo, 2004: 28).

El cambio en las lógicas del conflicto armado en Colombia, en cuanto a escenarios, objetivos, actores y estrategias bélicas, ha hecho que la migración forzada se transforme, de tal forma que actualmente no es posible hablar únicamente de las migraciones forzadas con trayectorias campo-ciudad (de lo rural a lo urbano), sino que se debe reconocer la existencia de una variación en esta lógica de movilidad impuesta: la migración forzada al interior de una misma ciudad. Esto ha generado varias tensiones, pues no resulta «sencillo» que ciudades capitales como Bogotá, Cali o Medellín, se reconozcan como centros expulsores de población por causa de la violencia sociopolítica, o que en ellas se admita la presencia, el accionar y la confrontación de actores armados (legales e «ilegales») tal como se manifiesta claramente en contextos rurales 2 . El resultado de estas tensiones es la invisibilidad que las ciudades están otorgando a un amplio sector de personas desarraigadas de sus territorios rurales. Las ciudades aún no reconocen que la migración forzada al interior de sus espacios urbanos sea un fenómeno social que amerita el diseño de políticas públicas para atender el desastre que la violencia está creando en un entorno «civilizado»: la ciudad.

También es importante mencionar que la población que está siendo re-desplazada de las zonas en las que se han reasentado en las ciudades — por lo general se trata de zonas periféricas-, está expuesta no solo a la tragedia que implica un nuevo éxodo, sino a patrones de exclusión y riesgos propios de una dinámica urbana. Por tal razón resulta fundamental reflexionar sobre el fenómeno de la migración forzada al interior de las ciudades en Colombia, un problema que aún no ha sido abordado como neurálgico en las acciones integrales de reducir los riesgos urbanos debido a su poco conocimiento y formas de intervención. Como académicos tenemos el reto de proporcionar elementos para el diseño de planes de mejoras, que para el caso que trataré en esta sección, tiene que ver con el reconocimiento del fenómeno, el diseño de políticas públicas que lo atiendan y el imperativo de conducir la gestión urbana a un lugar en el que se evite la proliferación de vulnerabilidades para un gran número de personas perseguidas

2 Al respecto ver las declaraciones de la Secretaria de Gobierno de Bogotá: revista Semana (2011). 
hasta en la ciudad por el accionar de los violentos. La migración forzada al interior de las ciudades como desastre de un desastre mayor (la migración forzada) nos pone en el imperativo de pensar y reflexionar sobre los desastres que la guerra sigue creando en Colombia. En un contexto aún de conflicto armado ¿̇cómo podemos pensar en políticas posdesastres?

\section{1. La migración forzada al interior de las ciudades}

La migración forzada al interior de las ciudades se ha venido definiendo en Colombia ${ }^{3}$ como aquella forma específica de migración forzada, que resulta de la articulación del conflicto armado con dinámicas de violencia urbana y que se expresa en los trayectos que al interior de una misma ciudad, una persona o un grupo de personas se ve obligado a recorrer al huir por causa de hechos de fuerza o coacción. La presencia y el accionar de actores armados del conflicto armado en la ciudad — como parte de su estrategia de expansión y dominio territorial- y los contextos urbanos caracterizados por desigualdad, exclusión, conflictos y violencias - que representan ambientes propicios para el ingreso y establecimiento de estos actores armados - son dos aspectos centrales en la definición que se ha hecho de este tipo de migración.

Según la propuesta de las investigadoras colombianas Gloria Naranjo y Deicy Hurtado, históricamente las ciudades colombianas se han formado a partir de la exclusión y de la lucha por el reconocimiento y por el derecho a la ciudad. En este sentido las autoras aseguran que los procesos de urbanización han estado marcados por la segregación socioespacial y han respondido a una lógica de «colonización urbana», que explican de la siguiente manera:

En la base de la urbanización y estructuración física y social de la gran mayoría de ciudades colombianas se encuentran procesos socioculturales, políticos y organizativos que, con Jacques Aprille, bien podríamos denominar colonización urbana. Se trata de una suma de acontecimientos, donde se destaca la ocupación de zonas deshabitadas de las ciudades mediante tomas, invasiones o posesiones, pero también diversas relaciones con urbanizadores piratas, partidos políticos e instituciones estatales. La construcción de territorios barriales por vía de la colonización urbana ha estado marcada por una relación de conflicto con el Estado y con el resto de la sociedad urbana. Es decir, el sentido de co-pertenencia se construye, necesariamente, a partir del conflicto por el uso y ocupación del espacio urbano, que es desigual por la relaciones de poder existentes, y es allí donde han construido y reconstruido sus formas de relacionamiento (Naranjo \& Hurtado, 2004: 11).

3 En Colombia se usa la expresión Desplazamiento Forzado Intraurbano. Para un entendimiento mayor del término en este artículo lo manejo como Migración Forzada al Interior de las Ciudades. 
Para estas autoras la ciudad se presenta entonces como un contexto en el cual hay una constante disputa por el territorio y uso del suelo, en la que pobladores que llegan deben «colonizar» espacios para hacerse a un lugar en ella. Sobre estos pobladores que llegan, que es el caso de los desplazados forzadamente, las autoras afirman que son percibidos como un problema para la ciudad, desconociendo su realidad y las razones por las cuales se encuentran en esas situaciones de precariedad y necesidad, que entre otras, es el sistema mismo de concentración de propiedad, uso del suelo y desigualdad social propios del entorno urbano.

Migrantes y desplazados expulsados a la ciudad, no pueden verse más como los disruptores del orden, como los que han venido a alterar la «coherente» estructura urbana; ellos son el resultado de un orden societal injusto, intolerante, que ha perpetuado patrones de concentración de la propiedad y del ingreso y tolerado altos índices de pobreza y miseria. En fin, son el producto también de un Estado que, sumido en un burocratismo y una corrupción extrema, pierde aceleradamente su capacidad de control cediendo el paso a otros actores (armados la más de las veces) para que tomen decisiones sobre el devenir de la población civil a la que someten e intimidan (Naranjo \& Hurtado, 2004: 11).

El papel que el Estado colombiano ha jugado para los migrantes y desplazados que llegan a la ciudad es también importante en el sentido que este no tiene el control y la soberanía sobre algunos de los territorios urbanos y por lo tanto no puede garantizar la seguridad y el libre ejercicio de los derechos ni de los habitantes de la ciudad, ni de los que llegan a esta. Al contrario, en muchos casos se ha comprobado que el Estado facilita el accionar de actores armados o no ofrece la suficiente resistencia como para que estos no cumplan con sus objetivos. De esta manera se crea un ambiente en el cual los diferentes actores armados, propios del conflicto armado y los propios de los conflictos y violencia de la ciudad (bandas, pandillas, etc.) pueden articularse para complejizar sus relaciones y hacer difusa su presencia y su forma de actuar. Es por esto que Naranjo reconoce que

lo cierto es que ambas [violencias] entran en interacción para fortalecerse y robustecerse y la llamada violencia difusa se convierte en un excelente escenario para ampliar el accionar de la violencia organizada (Naranjo, 2004: 285).

La ciudad se convierte entonces en un espacio en el cual se mezclan varios tipos de violencia y actores que la ejercen, provocando entre otras cosas, la migración forzada dentro de esta y al mismo tiempo recibiendo constantemente migrantes y desplazados forzados que llegan con la intención de encontrar un lugar en ella, así sea en la periferia. Estas se caracterizan generalmente por ser zonas de alto riesgo, cuyos habitantes (nuevos y viejos) se encuentran en un estado de alta vulnerabilidad. Por lo tanto, la ciudad también se entiende como agudizadora de la vulnerabilidad e invisibilidad de la migración forzada al considerar que los migrantes forzados que llegan representan un problema, un «exceso innecesario», en vez de reconocer la grave situación en la que se encuentran y brindarles atención y protección adecuada para que se integren y encuentren un lugar en la ciudad. 
Además de los anteriores contextos explicativos, resulta relevante considerar también los intereses de actores que no necesariamente están armados, pero que sí tienen un impacto en la generación de la migración forzada en las ciudades. Estos pueden ser actores políticos o de redes de economías ilegales que tienen intereses políticos (obtención de poder y control) o económicos (economías ilegales, tráfico de drogas y armas, captura de recursos) que, por alcanzar un objetivo específico de acuerdo a sus intereses, aportan a la generación de la migración forzada o al contexto urbano conflictivo en el cual esta se genera. En este caso son megaproyectos, proyectos de infraestructura, corredores estratégicos, planes de desarrollo nacionales, regionales y locales, los que juegan un papel importante y enmarcan los intereses de los actores involucrados.

\section{RECONOCIMIENTO DE LA MIGRACIÓN FORZADA EN LA CIUDAD: PANORAMA NACIONAL}

\section{1. Algunos antecedentes de la migración forzada en la ciudad}

En 1984 el Estado colombiano, a través del decreto 1547 del 21 de junio, creó el Fondo Nacional de Calamidades. En este decreto se definió que una catástrofe era: toda situación de emergencia que altere gravemente las condiciones normales de la vida cotidiana en una área geográfica o región del país determinada y que, por lo mismo, requiera de la especial atención de los organismos del Estado y de otros de carácter humanitario o de servicio social. Las situaciones de emergencia [...] pueden ser causadas por: a) Fenómenos naturales o artificiales de gran intensidad o violencia; b) Sucesos infaustos únicos o repetidos; c) Enfermedades o afecciones de carácter epidémico; d) Actos de hostilidad o conflictos armados de alcance nacional o internacional, que afecten a la población (Decreto 1547 de 1984, Artículo 1).

Este decreto es la base para que en el año 1989, se organizara el Sistema Nacional para la prevención y Atención de desastres, creado a través del Decreto 919 de 1989 (Art. 70). La idea de catástrofe se plantea ahora como:

daño grave o [...] alteración grave de las condiciones normales de la vida en un área geográfica determinada, causada por fenómenos naturales y por efectos catastróficos de la acción del hombre en forma accidental, que requiera por ello de la especial atención de los organismos del Estado y de otras entidades de carácter humanitario o de servicio social (Decreto 919 de 1989. Art. 18).

Bajo esta definición el Gobierno de Virgilio Barco, creó el Comité Nacional para la prevención de Desastres, el Plan Nacional para la prevención y Atención de desastres, así como una serie de comités operativos y técnicos de carácter nacional y regional para la atención de desastres. Esta es la primera institucionalidad creada para atender la migración forzada en Colombia entendida como un 
desastre natural. Varias décadas después, el fenómeno de la migración forzada persiste, a punto tal que ha sido catalogado como una crisis humanitaria, y la institucionalidad que la atiende se ha transformado notablemente. Sin embargo, una nueva variedad de migración está siendo reconocida en el país en los últimos años: la que sucede al interior de una misma ciudad.

En mayo de 2001, 180 familias desplazadas que vivían en el asentamiento El Esfuerzo ${ }^{4}$, de Medellín 5 , fueron re-desplazadas por integrantes de las Autodefensas Unidas de Colombia cuando se disputaban este territorio con la Banda de Frank6. El trayecto seguido por estas familias fue al interior de la misma ciudad y el fenómeno se explicó como fruto de la agudización de la confrontación armada en Medellín7. Así relató este evento Atehortúa (2007):

Las amenazas y el posterior incendio de los ranchos [el 1 de mayo] produjeron, en menos de tres semanas, el desplazamiento masivo de todo el asentamiento [...] el incendio fue denominado por los mismos habitantes del sector y por algunos medios de comunicación como un hecho que había sido anunciado por el actor armado y que estaba en conocimiento de las autoridades administrativas de los municipios de Bello y Medellín [...] Por fuera de las personas que recurrieron a familiares, vecinos y amigos de la ciudad, luego de dejar el asentamiento, se pueden identificar dos grupos que de forma colectiva buscaron refugio en el tejido urbano. El primer grupo, cerca de cuarenta familias [...] se dirigieron a La Honda, un asentamiento de población en situación de desplazamiento en el centroriente de la ciudad. La evacuación y ubicación temporal [del segundo grupo]; es atendida por la administración del municipio de Bello; las personas son acogidas en dos sitios: -El Coliseo Tulio Ospina y Casa Betania- y carpas (Atehortua, 2007: 125-126).

Este re-desplazamiento, fue la primera noticia que se conoció en el país como desplazamiento forzado masivo (migración forzada masiva) dentro de un contexto urbano y con ello se supo también que, así como ocurre con el desplazamiento forzado con trayectoria del campo a la ciudad, la experiencia de pérdida y desarraigo está presente en la vida de las personas que se desplazan dentro de una misma ciudad, pero con un impacto adicional: «la pérdida de un derecho conquistado a través de los años por los pobladores urbanos residentes en sectores marginales o no regularizados: el derecho a la ciudad» (Sánchez, 2008: 167) y todo lo que ese término implica en relación con varios temas como los reasentamientos,

4 El Esfuerzo era un asentamiento nucleado, en Medellín, establecido en terrenos que fueron invadidos por población en situación de desplazamiento a mediados de los años 1990. Para profundizar sobre este caso, ver: Atehortúa Arredondo, 2007; Sánchez, 2008.

5 En este mismo año, la Defensoría del Pueblo señala que 22 familias del barrio Pablo Acuña, en Barrancabermeja, fueron desplazadas intraurbanamente por la disputa territorial entre milicias populares y las autodefensas (ver: Arboleda, 2004).

6 Sobre la presencia de las AUC en Medellín y concretamente sobre la disputa territorial entre las AUC y la banda de Frank ver: Atehortúa, 2007; Granada Vahos, 2003; Arboleda, 2004.

7 Ver por ejemplo: Sánchez, 2008. 
el uso del suelo, la vivienda y el ejercicio de ciudadanías. Sin embargo, a pesar de la gravedad y magnitud de este caso, no se desplegó ninguna acción o respuesta institucional en función de su reconocimiento, y su cubrimiento en los medios quedó relegado a unas reducidas notas en la prensa regional8.

Un año después, en el 2002, se produjo un «nuevo» desplazamiento masivo bajo las mismas características: expulsión de población asentada en Medellín y con trayectorias de movilidad forzada al interior de la ciudad. Se trató del caso del Barrio El Salado en la Comuna 13 de Medellín. Así documentó este caso el Grupo de Memoria Histórica de la Comisión Nacional de Reparación y Reconciliación9:

El sábado 29 de junio de 2002, paramilitares del Bloque Cacique Nutibara (BCN) de las Autodefensas Unidas de Colombia (AUC) incursionaron en la parte alta del barrio El Salado, sectores 6 y 7, en la Comuna 13 de Medellín. Durante la incursión asesinaron a un habitante, incendiaron nueve ranchos, amenazaron, maltrataron física y verbalmente a los residentes y forzaron el desplazamiento de aproximadamente 170 de las 200 familias que habitaban el sector (Grupo de Memoria Histórica-Comisión Nacional de Reparación y Reconciliación, 2011: 13).

Para las relatoras de este informe10, las circunstancias en las que ocurrió este desplazamiento, las diversas formas de terror empleadas y las respuestas institucionales frente a su reconocimiento constituyen un caso ilustrativo del desplazamiento forzado en contextos urbanos. De hecho, y según la Defensoría del Pueblo, este caso «tiene particular importancia en el reconocimiento del desplazamiento intraurbano como parte del fenómeno del desplazamiento forzado por el conflicto armado interno, y, en consecuencia, en el reconocimiento de los afectados como personas en situación de desplazamiento, sujetos de protección y atención en el marco de la Ley 387 de 199711》 (Arboleda, 2004: 42), fruto del fallo que la Corte Constitucional profirió el 23 de abril de 2003 a través de la Sentencia T-268 (Corte constitucional, 2003), después de que en julio de 2002 la Red de Solidaridad Social — hoy Acción Social— se negara a registrar a esta población como víctima del desplazamiento forzado12.

8 Ver por ejemplo El colombiano. Tierra arrasada, drama que persigue a los desplazados (2 de mayo de 2001). Citado en: Atehortúa, 2007.

9 Sobre este mismo caso también puede verse: Atehortúa, 2007; Sánchez, 2008; Arboleda, 2004; Corte Constitucional Sentencia T-268 de 2003.

10 Luz Amparo Sánchez, Marta Inés Villa, Pilar Riaño, Martha Nubia Bello, Ana María Jaramillo, Sandra Milena González.

11 Ley por la cual se adoptan medidas para la prevención del desplazamiento forzado; la atención, protección, consolidación y estabilización socioeconómica de los desplazados internos por la violencia en la República de Colombia.

12 Para profundizar sobre este proceso jurídico ver: Grupo de Memoria Histórica-Comisión Nacional de Reparación y Reconciliación, 2011; Atehortúa, 2007; Corte Constitucional, 2003. 


\section{2. Cifras de la migración forzada al interior de las ciudades: panorama nacional}

Si bien los dos casos revisados anteriormente se presentaron en Medellín ${ }^{13}$, y el del barrio El Salado representa el avance más significativo en términos de interpretación de la migración forzada en las ciudades como una tipología de migración forzada interna (Grupo de Memoria Histórica-Comisión Nacional de Reparación y Reconciliación, 2011: 235), este fenómeno no es «exclusivo» de esta ciudad, ni solo se presentó durante los años 2000-2002. Así lo demuestran los datos de la entonces Acción Social (ahora Departamento de la Prosperidad Social). Para esta entidad estatal, entre 1980 y agosto de 2013 se ha presentado un total de 123903 casos en el Registro Único de Víctimas — RUV — de personas afectadas por la migración forzada intraurbanamente en comparación con un total de 5027964 personas registradas como víctimas de migración forzada. Esto significa que, durante este periodo, el 2,46\% de la población expulsada en el país ha sido víctima de esta forma de violencia. Esta modalidad mostró un proceso de ascenso paulatino desde los inicios de los años 1990, presentando un comportamiento más dinámico luego de 1994, lo cual coincide con el escalamiento de la guerra en el país que se expresó en las múltiples ofensivas de los grupos guerrilleros y en la vehemente respuesta paramilitar. Para la siguiente década el incremento es alarmante, especialmente durante los años 2002, 2006, 2008 y 2011:

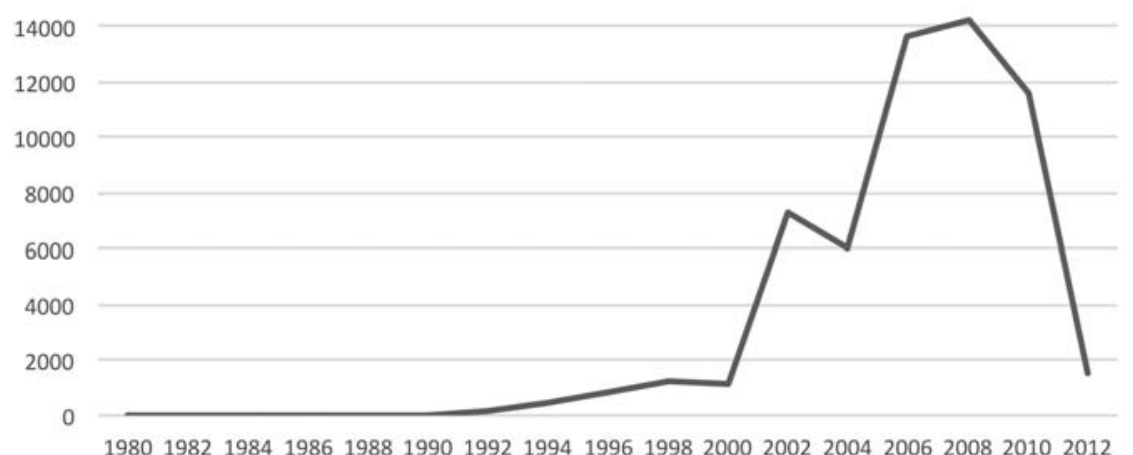

Figura 1 - Registros de migración forzada intraurbana 1980-2013

Gráfica que muestra el comportamiento de la migración forzada intraurbana en Colombia durante el periodo 1980-2013

Fuente: Registro Único de Víctimas

13 Para esta misma ciudad habría que agregar el desplazamiento masivo que en el año 2003 se presentó en el asentamiento de La Honda, ocasionado por el desarrollo de la Operación militar Estrella VI en el marco de la «pacificación de la ciudad». Para profundizar sobre este caso ver Atehortúa, 2007. 
Ahora bien, resulta interesante señalar que entre 1980 y 2002 las cifras de la migración forzada intraurbana se presentan de forma ascendente lo que guarda estrecha relación con la dinámica histórica del conflicto armado interno en Colombia. Ciertamente, durante los años 1980 las FARC-EP inician una etapa de crecimiento exponencial a través del desdoblamiento de sus frentes (Ferro \& Uribe, 2002). De igual modo, los grupos paramilitares empiezan a tomar fuerza en regiones con previo dominio guerrillero (Romero, 2007). En síntesis, para la década de los años 1980 los grupos armados ilegales se encuentran en un momento de ascenso militar que los prepara para el escalamiento de la guerra que caracteriza los años 1990. En 1995 se inicia el proceso de organización político-militar de las AUC que coincide con un conjunto de victorias militares alcanzadas por las FARCEP para esta época: Patascoy (diciembre de 1997), Miraflores (agosto de 1998), El Billar-Caquetá (marzo de 1998), entre otras (Granada et al., 2009). Comienza entonces la expansión paramilitar que se ubica entre los años 1997 y 2002.

Para el año 2003 las cifras de migración forzada intraurbana comienzan a descender. De 7297 registros de personas expulsadas intraurbanamente que se presentan en el año 2002 se pasa a un número de 4336 registros en 2003, 5986 en 2004 y 5981 en 2005. En esta etapa se puede hablar de una cierta hegemonía paramilitar que se mantiene hasta el año 2005 con el proceso de desmovilización de las mismas. Para los años 2006 y 2008 se tiene otro ascenso en las cifras de migración forzada intraurbana que descienden en 2009 cuando se presenta un número de 7302 registros. Finalmente, el último pico que se presenta, como ya se ha señalado, corresponde al año 2011. El ascenso de las cifras en este último periodo puede estar relacionado con los resultados del fallido proceso de desmovilización paramilitar, con lo que Granada et al. (2009) denomina un «desgaste de la política de seguridad democrática» y con la aparición en la escena de las llamadas bandas criminales - Bacrim-.

Las ciudades más afectadas por este fenómeno en el periodo 1980-2013, en orden de magnitud, corresponden a:

\begin{tabular}{|l|l|l|}
\hline \multicolumn{1}{|c|}{ CIUDAD } & \multicolumn{1}{c|}{ DEPARTAMENTO } & n. ${ }^{\text {D }}$ DE REGISTROS 1980-2013 \\
\hline Buenaventura & Valle del Cauca & 33706 \\
\hline Medellín & Antioquia & 31586 \\
\hline Timbiqui & Cauca & 2278 \\
\hline Quibdó & Choco & 2092 \\
\hline Bogotá, D.C. & Bogotá, D.C. & 1610 \\
\hline San Onofre & Sucre & 1278 \\
\hline Apartado & Antioquia & 1230 \\
\hline Valledupar & Cesar & 1174 \\
\hline Riosucio & Choco & 1014 \\
\hline San José Del Guaviare & Guaviare & 929 \\
\hline
\end{tabular}


En términos de migración forzada intraurbana de carácter individual que se presentó durante el periodo 1980-2013 vemos que: Medellín (Antioquia) presenta un registro de 31027 personas expulsadas individualmente, Buenaventura (Valle del Cauca) un total de 23835 personas expulsadas individualmente, Bogotá (Cundinamarca) 1611 personas, Quibdó (Choco) 1610 personas y Timbiquí (Cauca) 192. En estas ciudades, el registro más alto de migración intraurbana de carácter masivo (equivalente a 10 familias o 50 personas) corresponde a: Buenaventura (Valle del Cauca) con un registro de 10204 personas expulsadas masivamente, Medellín (Antioquia) con 624 registros, Timbiquí (Cauca) con 2093 registros, Quibdó (Choco) con 620 registros y finalmente Bogotá (Cundinamarca) con un registro de 0 personas expulsadas masivamente.

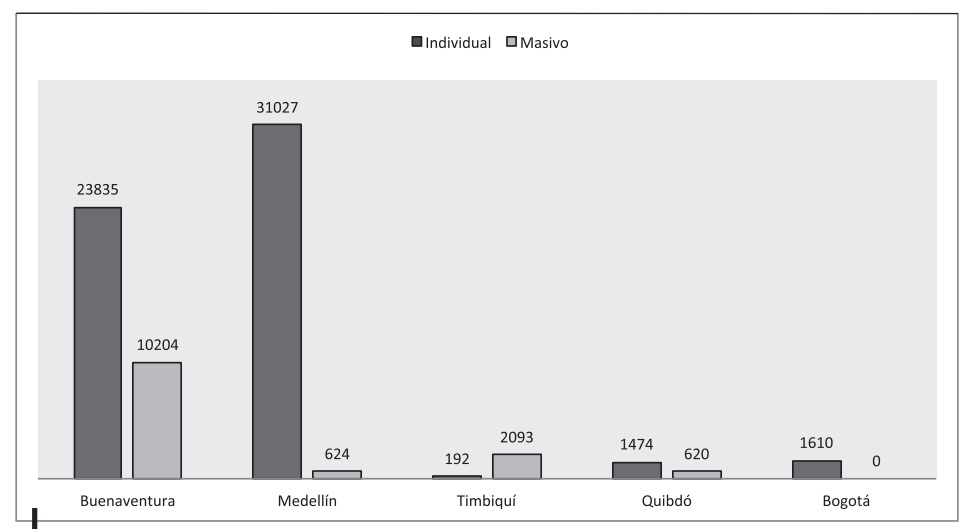

Figura 2 - Migración intraurbana individual vs. migración intraurbana masiva 1980-2013. Principales ciudades afectadas

Gráfica que muestra comparativamente las principales ciudades afectadas por la migración forzada intraurbana en Colombia durante el periodo 1980-2013

Fuente: Datos Registro Único de Víctimas

Respecto a los presuntos autores de los desplazamientos forzados intraurbanos, el RUV registra entre los actores más desplazadores a grupos guerrilleros y grupos paramilitares. Sin embargo, la categoría de no identifica, es decir, cuando la víctima no reporta a su presunto victimario, cuenta con un número bastante alto de registros: 


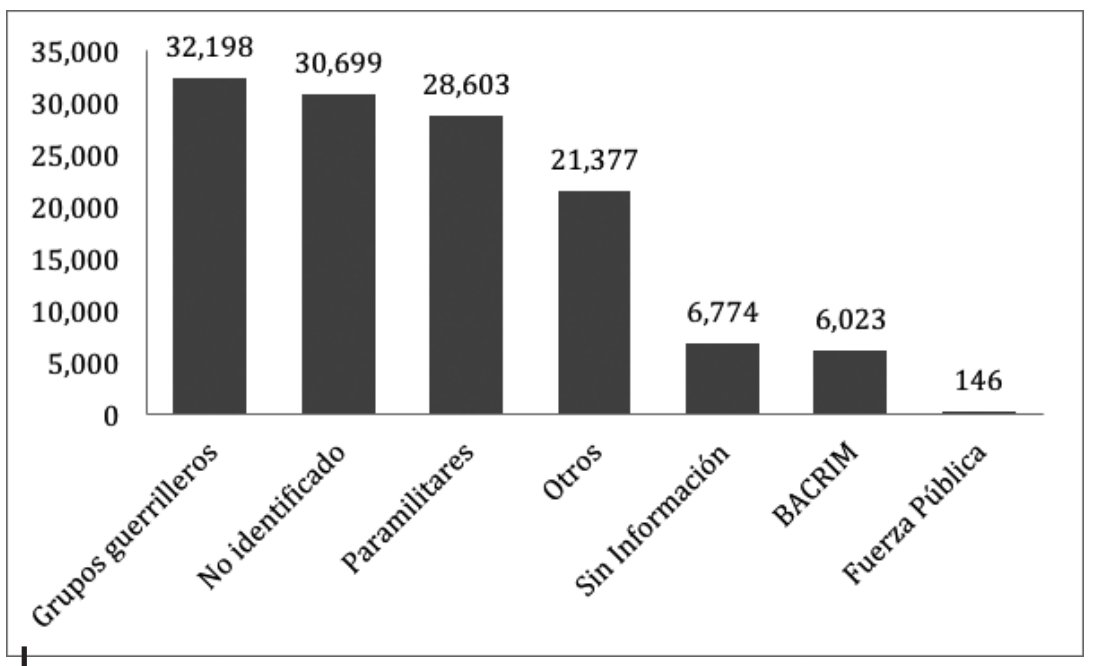

Figura 3 - Total de personas desplazadas intraurbanamente y participación por actor armado (antes de 1980-2013)

Gráfica que muestra el total de personas afectadas por la migración forzada intraurbana y su relación con los actores armados responsables del hecho para el periodo 19802013

Fuente: Registro Único de Víctimas

En términos nacionales no es fácil ubicar a un actor que prevalezca como autor de la migración forzada intraurbana. Los grupos desplazadores son aquellos que han resultado protagonistas en el conflicto armado interno del país: grupos guerrilleros y paramilitares. Junto a estos, aparecen registros relacionados con Bacrim y Fuerza Pública. Pese a esto, parece que el actuar de grupos que hacen parte del conflicto armado interno no está claro en términos de la migración forzada intraurbana puesto que las personas afectadas por este fenómeno no pueden identificar a su agresor, o por el contrario, es tan clara la responsabilidad de un grupo u otro en estos desplazamientos que las personas que se registran en el RUV prefieren omitir la identidad del agresor por miedo a ser victimizados de nuevo.

\section{REPRESENTACIÓN Y RECONOCIMIENTO DE LA MOVILIDAD FORZADA EN LOS ESCENARIOS URBANOS}

Desde las instituciones estatales delegadas para el seguimiento y evaluación de la política pública sobre el desplazamiento forzado en Colombia14, la migración

14 Defensoría del Pueblo, Procuraduría General de la Nación y Gobierno Nacional a través del Sistema Nacional de Atención Integral a la Población Desplazada —SINAIP - (Ministerio del interior y de Justicia, Ministerio de Hacienda y Crédito Público, Departamento Nacional de Planeación, Ministerio de Defensa Nacional, Ministerio de Educación, Ministerio de Agricultura y Desarrollo Territorial, Instituto Colombiano de Bienestar Familiar) dirigido por Acción Social. 
forzada en las ciudades se empieza a referenciar en el año 2002. Este año, la Defensoría del Pueblo no solo remite a la Unidad Territorial de Antioquia de la Red de Solidaridad Social el caso de las familias desplazadas del asentamiento El Salado, en Medellín, sino que, ante la negativa de esta entidad de registrar a estas familias como víctimas del desplazamiento forzado, inicia un proceso jurídico que involucró no solo la solicitud de demanda ante la Corte Constitucional, sino que además, organizó una Audiencia Pública Defensorial (3 de octubre de 2002) sobre el desplazamiento intraurbano ${ }^{15}$.

En el año 2004, la Defensoría presenta un informe sobre esta modalidad de desplazamiento forzado y la conceptualiza como una consecuencia del conflicto armado en las ciudades. Para esta entidad, la migración de pobladores urbanos al interior de una misma ciudad está asociada con el desplazamiento forzado por el conflicto armado interno y concretamente por la intensificación, en las zonas marginales de las ciudades, del accionar bélico de «milicias urbanas, grupos paramilitares y bandas delincuenciales que se disputan el control de territorios y habitantes, así como de enfrentamientos permanentes entre estos grupos, y entre la Fuerza Pública y los mismos» (Arboleda, 2004: 7).

En el año 2006, es la Procuraduría General de la Nación la que se refiere al tema de la migración forzada en las ciudades (Informes n. ${ }^{\circ} 5$ y n. ${ }^{\circ} 6$, Procuraduría General de la Nación, 2006b), advirtiendo en sus informes el rechazo de esta modalidad en los registros de Acción Social por no considerarla parte del desplazamiento forzado en el país16. Así lo señala esta entidad:

La PGN ha podido probar que, [...] desde sus inicios el conteo gubernamental ha tendido al subregistro. Según datos suministrados a la PGN por las unidades territoriales de la Red de Solidaridad, ahora Acción Social, el subregistro en ocasiones ha alcanzando un porcentaje de hasta el 33.42\%. Así ocurrió en el año 2004, en el cual de 138.888 personas que solicitaron ser registradas, un total de 33.105 no fueron aceptadas como desplazadas y, por tanto no fueron incluidas en el Registro Único de Población Desplazada. Las principales causales de rechazo están asociadas con la noción crecientemente restrictiva de desplazamiento forzado con la que opera Acción Social para alimentar el SUR (Sistema Único de Registro). Por ejemplo, las solicitudes originadas por desplazamientos intra-urbanos, intra-veredales y, en el caso de grupos étnicos, dentro de los territorios colectivos, tienden a ser rechazadas por no considerarlas

15 Sobre este proceso ver: Grupo de Memoria Histórica-Comisión Nacional de Reparación y Reconciliación (2011). Sobre este proceso y otros relacionados con los casos de El Esfuerzo y La Honda, ver Atehortúa, 2007.

$16 \mathrm{Al}$ respecto también puede verse el Auto 218 de 2006 emitido por la Corte Constitucional que plantea que los problemas del Registro Único de Población Desplazada persistían, especialmente en aquellos casos relacionados con «segundos desplazamientos, desplazamientos intraveredales e intraurbanos, desplazamientos originados en operaciones de policía o militares en las que no se ha incluido un componente humanitario ni un plan de contingencia humanitario, así como las solicitudes de registro después del primer año de ocurrido el desplazamiento» (Auto 218, 2006. Considerando 2.1.). 
como desplazamientos propiamente dichos. Lo mismo sucede cuando el desplazado individual y, en algunos casos, los integrantes de desplazamientos masivos, han conseguido retornar en un plazo relativamente breve a su lugar de origen, en cuyo caso Acción Social ha tendido a no incluirlos en el registro (Procuraduria Nacional, 2006a: 5-6) [Negrillas fuera del texto]

Para este mismo año, la Defensoría del Pueblo emite su decimocuarto informe al Congreso de la República y en este documento identifica que

Los desplazamientos intraurbanos son más intensos en Bogotá, Soacha, Buenaventura, Bucaramanga y otras grandes y medianas urbes, dentro de las zonas periféricas, que, además, se caracterizan por ser receptoras de población víctima de desplazamientos forzados donde las milicias de la guerrilla y las bandas emergentes se disputan el control de negocios legales e ilegales; allí, las víctimas sufren un segundo o tercer desplazamiento en la mayoría de los casos (Defensoría del Pueblo, 2006: 74).

Desde el año 2004 y hasta la fecha, la Defensoría del Pueblo a través de la «Defensoría delegada para la evaluación del riesgo de la población civil como consecuencia del conflicto armado. Sistema de alertas tempranas —SAT—», ha emitido una serie de informes de riesgo en los que advierten la existencia de la migración forzada en las ciudades. Bogotá, Soacha, Medellín, Buenaventura, Bucaramanga y Cartagena han sido ciudades objeto de estos informes ${ }^{17}$.

Para el caso de la prensa, en los diarios El Tiempo, El Espectador y la revista Semana, la migración forzada en las ciudades puede rastrearse a través de tres grandes bloques temporales: i) antecedentes (1997-2000); ii) surgimiento y menciones esporádicas (2000- 2007); y iii) aumento de frecuencia e intensidad (2007-2011). El primero ilustra algunos textos que antecedieron el surgimiento del desplazamiento forzado en la ciudad, anunciando su posible aparición, alertando sobre la complicación de orden público y seguridad en las ciudades colombianas, o diagnosticando el desarrollo del conflicto armado hacia la ciudad.

El segundo tiene algunas particularidades. En el año 2002 la migración forzada al interior de las ciudades empieza a hacerse visible, ejemplo de ello son algunas notas en el diario El Espectador y El Tiempo y en la revista Semana en relación con los enfrentamientos entre bandas y milicias en la ciudad de Medellín18. La hipótesis de estos medios de comunicación es que «en la medida en que la guerra se fue acercando a las ciudades, comenzó a registrarse un desplazamiento intraurbano» (Revista Semana, 2002b). En agosto de 2006, empieza a hacerse referencia al «descubrimiento» del fenómeno en la ciudad de Bogotá (Periódico El Tiempo, 2006). Finalmente, tres meses más tarde también se menciona la situación de «desplazamiento intraurbano en la ciudad de Buenaventura, en la cual son desplazadas 1.000 personas de sus hogares».

17 Ver por ejemplo los Informes de Riesgo n. ${ }^{\circ}$ 062-02; 013-04; 053-05; 036-06; 948-06; 012-07; 02108.

18 El Tiempo, 23 de agosto 2000; El Espectador, 2011; Rojas, 2002; Semana, 2002a: «Guerra en las comunas». Octubre 20. Sección Nación. Disponible en: http://www.semana.com/nacion/guerracomunas/66056-3.aspx [Visitado el 10 de septiembre de 2011]; Semana, 2002b. 
No obstante, es a partir de octubre de 2007 que aumenta el registro sobre este tipo de migración forzada, al incrementar la frecuencia e intensidad con las que se informa sobre el fenómeno. Este es mencionado, por ejemplo en el diario El Tiempo, más constantemente y en casos concretos (como de octubre de 2007 a marzo de 2008, noviembre de 2008 o junio a noviembre de 2010), en lo que se puede ver una mayor intensidad en el tratamiento de la migración forzada en las ciudades. Se puede ver cómo la migración forzada en las ciudades se menciona de forma más continua y constante, se va volviendo recurrente, y el discurso alcanza algún grado mayor de profundidad, en la medida en que se discute sobre el fenómeno y la respuesta estatal frente al mismo, en vez de hacer una simple mención de su existencia en el contexto de violencia en la ciudad (Periódico El Tiempo, 2008; 2010a; 2010b; 2011).

Si en el año 2002 los medios de comunicación evidenciaron la existencia de una «guerra» dentro de los espacios urbanos, con ocasión de la urbanización del conflicto armado y las nuevas estrategias de control territorial de los actores armados en disputa, durante los años 2010-2011, se ve que los medios de comunicación enfatizan en la idea de que el fenómeno de la migración forzada al interior de las ciudades responde a dos situaciones:

i) A un problema político de seguridad ciudadana que no se resolvió con la desmovilización paramilitar19 y que aún no se ha resuelto a pesar de la implementación de políticas de militarización, principalmente, en las zonas más periféricas de la ciudad20. Este argumento está respaldado en aquella idea de que la instauración de un nuevo orden de seguridad en las márgenes de algunas ciudades como Medellín y Bogotá no está en manos de las Fuerzas Militares del Estado sino en una gran variedad de grupos armados y delincuenciales. Este factor explicativo de la inseguridad ciudadana también está profundamente relacionado con el creciente asesinato y amenazas a líderes de organizaciones sociales en situación de desplazamiento forzado que en la prensa se han venido registrando desde el año 2009.

ii) La migración forzada en las ciudades responde también a las profundas desigualdades sociales y económicas que se presentan en los bordes de las ciudades.

El caldo de cultivo para la proliferación de estos grupos han sido los amplios niveles de pobreza, en una ciudad a donde sigue llegando población desplazada y donde los niveles de pobreza crecen en las zonas de periferia (Periódico El Expectador, 2011).

19 Tal como señala esta nota de prensa: «el paramilitarismo se está reinventando en Colombia a través de formas de violencia que encuentran en las ciudades un escenario idóneo para reproducirse» (Azuero, 2008).

20 Como puede observarse en esta nota de prensa: «La crisis de seguridad que vive Medellín tiene inquietos a diversos sectores de la capital antioqueña. Los está impacientando no sólo la falta de efectividad de las medidas que ejecutan las autoridades para enfrentar la desenfrenada lucha por el control de amplios territorios urbanos que libran decenas de bandas armadas urbanas que en el pasado integraron las Autodefensas Unidas de Colombia (AUC), sino las afectaciones sociales y económicas que sufren por cuenta de esa situación» (Restrepo, 2010). 
Con base en estos dos grandes argumentos (seguridad y factores económicos), la prensa ha señalado que la migración forzada en las ciudades es un fenómeno que se presenta por:

La toma de las zonas más pobres de la ciudad por actores armados ilegales, que dominan micro territorios, con el uso de la fuerza y el control social y territorial... el desplazamiento intraurbano también tiene entre sus motivos la no colaboración con grupos armados ilegales, el ser testigo o tener conocimiento de delitos, haber sido víctima de atentados, la extorsión y el despojo de viviendas... Es común que las familias se resistan a abandonar sus domicilios y, en la mayoría de los casos, solo se desplacen «después de recibir amenazas directas o de atentar en contra de la vida de alguno de sus integrantes (Periódico El Espectador, 2010).

\section{A MODO DE CIERRE}

El recorrido hecho en este artículo sobre las dinámicas de la migración forzada en las ciudades de Colombia, permite establecer que este fenómeno se ha venido intensificando en el país y cada vez más genera múltiples impactos que afectan al conjunto de la población que habita las ciudades en zonas marginales o periféricas. Desde esta perspectiva, la migración forzada al interior de las ciudades no solo da cuenta de la confrontación armada, propia de un conflicto armado interno, sino que también da cuenta de un conflicto urbano, operacionalizado básicamente a partir de la complejidad de los dominios territoriales que se presentan en la ciudad. Estos dominios en la ciudad no pasan exclusivamente por acciones de confrontación armada. Los actores (legales e ilegales) recurren a una serie de prácticas de terror que no pasan necesariamente por acciones de violencia directa, sino muchas veces por acciones de amenazas, miedo, incertidumbre y desconfianza, bajo el control de actores armados que pretenden dominar la vida cotidiana. Esto revela, tal como lo señala Luz Amparo Sánchez (2008), que «el desplazamiento intraurbano hace parte de la dinámica de desplazamiento forzado interno que pervive en el país y que ha sido experimentado por varias generaciones; y por otro lado, que por lo menos para una buena parte de la población, las ciudades no son, como lo fueron en los años sesenta, un lugar que significa refugio y protección» (Sánchez, 2008: 176).

La migración forzada al interior de las ciudades también debe aportarnos a reflexionar sobre la relación ciudad-migración forzada. Al inicio de este artículo retomaba aquel planteamiento de entender los procesos migratorios forzados como parte del proceso de formación y establecimiento de las ciudades en Colombia. Esta propuesta se construye en contraposición a las visiones que estudian el desplazamiento forzado como un fenómeno desorganizador y desestabilizador de las ciudades. En este sentido, se busca entender la relación de las migraciones y la ciudad en una doble perspectiva: «a) desde el punto de vista de los desplazados, lo que ellos aportan y demandan a la ciudad (lo que los desplazados hacen con la ciudad); b) desde el punto de vista de la ciudad, lo que ella entrega o niega a 
los desplazados (lo que la ciudad hace con los desplazados)». Esta premisa hace que la relación entre el desplazamiento forzado y la ciudad tenga una mirada compleja en la que se deben «explorar las experiencias sociales y las formas de interacción e intercambio familiar, vecinal, urbano, las transacciones, las relaciones, la transposición y transferencia de límites entre lo legal y lo ilegal, lo formal y lo informal, las situaciones de hecho y los derechos y la ley» (Naranjo, 2004: 95).

En la exploración que hizo el Centro Nacional de Memoria Histórica (2014) respecto a las percepciones elaboradas en torno a la respuesta institucional recibida por parte de las víctimas de migración forzada intraurbana, identificaron que para estas víctimas la respuesta es insuficiente y precaria. Esto debido a que existe una institucionalidad poco preparada y sensibilizada frente al tema, unas rutas y procedimientos que no son claros para la población que intenta acceder a la oferta institucional y unos «cuellos de botella» que entorpecen el proceso, lo hacen lento y muchas veces ineficiente. La respuesta institucional resulta fundamental frente al tema de la migración forzada intraurbana pues como se ha venido exponiendo a lo largo del artículo, al ser esta un fenómeno que aún cuenta con poco reconocimiento y visibilización, la respuesta y atención al problema se tornan en un reto que es preciso adelantar para garantizar una respuesta integral, diferenciada y oportuna. Ahora bien, para afrontar el desafío propuesto no es suficiente con explorar las percepciones asociadas a la respuesta institucional; es necesario ir más allá y, a partir de estas percepciones, proponer recomendaciones de interés para trabajar y atender este problema.

En su informe nacional sobre este fenómeno, el Centro Nacional de Memoria Histórica, recomienda varios aspectos centrales con los cuales quiero cerrar este artículo:

La primera recomendación tiene que ver con la necesidad de visibilizar la migración forzada intraurbana como una modalidad de migración forzada y como un hecho victimizante. Así, para este centro de investigación estatal, resulta urgente que organizaciones sociales, líderes, lideresas, población víctima y funcionarios alcancen una mayor comprensión sobre este tipo de migración y lo incluyan en sus agendas de trabajo. Es necesario también llamar la atención de la academia, los medios de comunicación y otras instancias de generación de conocimiento, para que investiguen el tema, sus dinámicas, actores, expresiones, consecuencias y posibles soluciones.

Otro aspecto central en perspectiva de recomendación tiene que ver con la necesidad de fortalecer las instituciones del Estado encargadas de atender y reparar. Si se tiene una capacidad institucional instalada a nivel territorial que pueda efectivamente atender el volumen de demandas ciudadanas presentadas en términos de atención y asistencia a víctimas, sumadas a una visibilización y sensibilización frente al fenómeno, muy posiblemente los problemas relacionados con el subregistro puedan disminuirse. Ciertamente, el subregistro de población migrante forzada intraurbanamente, resulta un problema mayor no solo porque no se conoce las dimensiones reales del fenómeno sino porque imposibilita tener 
un universo certero de población que debe ser atendida. Así, la orientación de recursos humanos, técnicos y financieros destinados a la atención de esta población siempre serán sobre o subdimensionados e imprecisos. Por ello, se recomienda contar con registros ajustados para poder identificar las tendencias del fenómeno, sus dinámicas, en qué momento se presenta de forma más alarmante, cuáles son sus picos, etcétera. Esta información resulta fundamental para conocer el fenómeno, tomar medidas para su atención e, incluso, diseñar políticas de largo plazo que le permitan a la población víctima lograr estabilización socioeconómica y garantía de derechos. Entonces, es necesario trabajar en el fortalecimiento del registro para lograr cifras ajustadas que permitan establecer un panorama de trabajo, intervención y acción.

\section{Referencias citadas}

ARBOLEDA, S., 2004 - Desplazamiento intraurbano como consecuencia del conflicto armado en las ciudades, 75 pp.; Bogotá: Defensoría del Pueblo.

ATEHORTÚA ARREDONDO, C. I., 2007 - Caracterización del desplazamiento forzado intraurbano. Medellín 2000-2004; Medellín: Universidad de Antioquia. Trabajo de grado para optar a la maestría en Ciencias Políticas.

AZUERO, A., 2008 - Cuando morir ya no es noticia. Revista Semana, Febrero 02. Sección Opinión. Disponible en: http://www.semana.com/opinion/cuando-morir-nonoticia/109148-3.aspx [Visitado el 10 de septiembre de 2011].

BELLO, M. N. \& JIMÉNEZ O., S., 2008 - Dinámicas regionales del conflicto armado y el desplazamiento forzado. Ciudades: Bogotá, Soacha, Medellín, Cartagena, 79 pp.; Cartagena: Grupo de Investigación en Desarrollo Social-Gides, Universidad de San Buenaventura.

CENTRO NACIONAL DE MEMORIA HISTÓRICA, 2014 - Desplazamiento Forzado Intraurbano. Aproximaciones desde un enfoque de Memoria Histórica; Bogotá: $\mathrm{CNMH}$.

CONSULTORÍA PARA LOS DERECHOS HUMANOS Y EL DESPLAZAMIENTOCODHES, 2013 - Desplazamiento forzado intraurbano y soluciones duraderas. Una aproximación desde los casos de Buenaventura, Tumaco y Soacha; Bogotá: Colombia.

CONSULTORÍA PARA LOS DERECHOS HUMANOS Y EL DESPLAZAMIENTO-CODHES, 2014 - Desplazamiento forzado intraurbano y soluciones duraderas. Vol II: Bogotá, Cúcuta y Quibdó; Bogotá: CODHES.

CORTE CONSTITUCIONAL, 2003 - Sentencia T-268. Sala de Revisión sexta. 27 de marzo de 2003. M. P. Marco Gerardo Monroy Cabra.

CORTE CONSTITUCIONAL DE COLOMBIA, 2012 - Sentencia C-781. Actor: Gustavo Gallón Giraldo y otros. Ponente: Magistrada María Victoria Calle; Bogotá, Colombia.

DEFENSORÍA DEL PUEBLO, 2004 - Desplazamiento intraurbano como consecuencia del conflicto armado en las ciudades; Bogotá: Defensoría del Pueblo. 
DEFENSORÍA DEL PUEBLO, 2006 - Decimocuarto informe del defensor del pueblo de Colombia al Congreso de la República, 74 pp.; Bogotá: Defensoría del Pueblo.

FERRO MEDINA, J. G. \& URIBE RAMÓN, G., 2002 - El orden de la guerra, las FARC-EP: entre la organización y la política; Bogotá: Centro editorial Javeriano, CEJA.

GRANADA, S., RESTREPO, J. \& Vargas, A., 2009 - El agotamiento de la política de seguridad: evolución y transformaciones recientes en el conflicto armado colombiano. In: Guerra y violencias en Colombia: herramientas e interpretaciones (J. A. Restrepo \& D. Aponte, eds.): 27-124; Bogotá: Editorial Pontificia Universidad Javeriana.

GRUPO DE MEMORIA HISTÓRICA-COMISIÓN NACIONAL DE REPARACIÓN Y RECONCILIACIÓN, 2011 - La Huella invisible de la guerra. Desplazamiento forzado en la Comuna 13; Bogotá: Tauros Editorial.

GRANADA VAHOS, J. A., 2003 - Desplazamiento forzado intraurbano, contextualizado desde el conflicto socio-político armado en Medellín; Medellín: Universidad De Antioquia. Facultad De Ciencias Sociales y Humanas. Monografía de grado (trabajo social).

JARAMILLO A., A. M., VILLA M., M. I. \& SÁNCHEZM., L. A., 2004 -Miedo y desplazamiento: experiencias y percepciones, 244 pp.; Medellín: Corporación Región.

PROCURADURÍA GENERAL DE LA NACIÓN., 2006b - Sexto informe de la Procuraduría General de la Nación sobre el cumplimiento de las órdenes contenidas en la sentencia T-025 de 2004 y los autos 176, 177 y 178 del 29 de agosto de 2005 y 218 y 266 de 2006; Bogotá: Procuraduría General de la Nación.

NARANJO G., G., 2004 - Ciudades y desplazamiento forzado en Colombia. El reasentamiento de hecho y el derecho al restablecimiento en contextos conflictivos de urbanización. In: El desplazamiento forzado, Dinámicas De Guerra Exclusión Y Desarraigo: 279-310; Bogotá: Editorial Universidad Nacional De Colombia, Acnur.

NARANJO G., G. \& HURTADO G., D., 2004 - «El derecho a la ciudad. Migrantes y desplazados en las ciudades colombianas». De Paso. Rostros y Caminos. Revista de la mesa interinstitucional en torno al desplazamiento forzado por el conflicto armado en Caldas, 1: 7-14; Manizales: Gobernación de Caldas/ Universidad de Caldas.

OBSERVATORIO DEL PROGRAMA PRESIDENCIAL DE DERECHOS HUMANOS Y DERECHO INTERNACIONAL HUMANITARIO, 2010 - Diagnóstico de la situación de los municipios habitados por las comunidades afrocolombianas priorizadas por la Honorable Corte Constitucional en el Departamento Valle del Cauca; Bogotá: Vicepresidencia de la República de Colombia.

RESTREPO, J. D., 2010 - Se teje solución violenta a crisis de seguridad en Medellín. Revista Semana, Agosto 18. Sección Opinión. Disponible en: http://www.semana.com/ opinion/teje-solucion-violenta-crisis-seguridad-medellin/143189-3.aspx [Visitado el 10 de septiembre de 2011].

ROJAS, J., 2002 - Una sociedad en medio del colapso. Revista Semana, Septiembre 09. Sección Opinión. Disponible en: http://www.semana.com/opinion/sociedadmedio-del-colapso/65280-3.aspx [Visitado el 10 de septiembre de 2011].

ROMERO, M. (ed.), 2007 - Parapolítica. La ruta de la expansión paramilitar y los acuerdos políticos; Bogotá: Corporación Nuevo Arco Iris.

SÁNCHEZ, L. A., 2008 - El desplazamiento forzado intraurbano: negación del derecho a la ciudad. In: Poniendo tierra de por medio. Migración forzada de colombianos en Colombia, Ecuador y Canadá (P. Riaño \& M. Villa, Eds.): 173-213; Medellín: Corporación Región. 
La migración forzada al interior de la ciudades en Colombia: invisibilización en los contextos urbanos

URIBE, M. T., 2002 - El desplazamiento forzado interno —Notas para un debate-. In: Desde la región, n. 37: 2-3; Medellín: Corporación Región.

\section{Periódicos y revistas}

PERIÓDICO EL ESPECTADOR, 2008 - «Alarma en Ciudad Bolívar y los Altos de Cazucá. 'Águilas Negras' están en Bogotá», marzo 19. Sección Judicial. Disponible en: http:// www.elespectador.com/impreso/cuadernilloa/judicial/articuloimpreso-aguilasnegras-estan-bogota [Visitado el 15 de septiembre de 2011].

PERIÓDICO EL ESPECTADOR, 2010 - «Más de 2.300 personas se desplazaron dentro de Medellín en seis meses», julio 30. Sección Paz. Disponible en: http://www. elespectador.com/noticias/paz/articulo-216329-mas-de-2300-personas-sedesplazaron-dentro-de-medellin-seis-meses [Visitado el 15 de septiembre de 2011].

PERIÓDICO EL ESPECTADOR, 2011 - «Crítico panorama de violencia en la Comuna 13 de Medellín. Los jóvenes, en la mira», abril 10. Sección Judicial. Disponible en: http://www.elespectador.com/impreso/judicial/articulo-262099-los-jovenes-mira [Visitado el 15 de septiembre de 2011].

PERIÓDICO EL TIEMPO, 2000 - «Con armas consiguen casa propia», 23 de agosto de 2000.

PERIÓDICO EL TIEMPO, 2006 - «La toma de Bosa por parte de desplazados se convirtió en una prueba de resistencia», 11 de agosto de 2006.

PERIÓDICO EL TIEMPO, 2008 - «Los desplazados invisibles de Soacha». 13 de noviembre de 2008.

PERIÓDICO EL TIEMPO, 2010a - «El drama del desplazamiento intraurbano», 3 de julio de 2010.

PERIÓDICO EL TIEMPO, 2010b - «Desplazamiento intraurbano, otro reto», 11 de noviembre de 2010.

PERIÓDICO EL TIEMPO, 2011 - «Medellín aún desconoce desplazados intraurbanos por conflicto urbano», 8 de mayo de 2011.

REVISTA SEMANA, 2002a - «Guerra en las comunas», Octubre 20. Sección Nación. Disponible en: http://www.semana.com/nacion/guerra-comunas/66056-3.aspx [Visitado el 10 de septiembre de 2011].

REVISTA SEMANA, 2002b - «Un país que huye...», Diciembre 23. Sección Nación. Disponible en: http://www.semana.com/nacion/pais-huye/67267-3.aspx [Visitado el 10 de septiembre de 2011].

REVISTA SEMANA, 2011 - «En Bogotá no hay bandas criminales: secretaria de Gobierno», Agosto 20. Sección Seguridad. Disponible en: http://www.semana.com/nacion/ bogota-no-bandas-criminales-secretaria-gobierno/162700-3.aspx [Visitada el 10 de septiembre de 2011]. 